\title{
A Relevância da Obra de Simon Kuznets para o Debate sobre Distribuição de Renda desde o Pós-Segunda Guerra
}

\author{
The Relevance of Simon Kuznets' Work for the Income Distribution Debate since the \\ Post-Second World War
}

\section{Fernando Augusto Mansor de Mattos ${ }^{a}$}

\begin{abstract}
Resumo: O objetivo do artigo é tomar como referência a obra de Simon Kuznets para descrever aspectos importantes do debate sobre desigualdade econômica e distribuição de renda nos países desenvolvidos desde 1945. A primeira seção, baseada em Kuznets (1955), expõe seu modelo com simulações dos efeitos de mudanças de estrutura produtiva e de emprego sobre o perfil distributivo. A segunda apresenta o debate sobre distribuição de renda após 1980, quando ocorre a "reversão" da Curva de Kuznets. Na terceira, destaca-se o "debate do 1\% mais rico", que incorpora aspectos políticos para compreender a recente expansão da desigualdade nas economias desenvolvidas no século XXI. As conclusões apontam a relevância e atualidade de sua obra para o debate sobre distribuição de renda e desigualdade econômica.
\end{abstract}

Palavras-chave: Distribuição de Renda; Curva de Kuznets; Desigualdade Econômica Classificação JEL: D31; D33; E25; N30; P16

\begin{abstract}
The purpose of the article is to refer to the work of Simon Kuznets to describe important aspects of the debate on economic inequality and income distribution in developed countries since 1945. The first section, based on Kuznets (1955), presents his model with simulations of the effects of changes in productive and employment structure on the distributive profile. The second presents the debate on income distribution after 1980, when there was a "reversal" of the Kuznets Curve. In the third, the article highlights "the top 1\% debate", which seeks to incorporate political and social aspects to understand the recent expansion of income inequality in developed economies in the 21 st century. The conclusions point to the relevance and currentness of his work for the debate on income distribution and economic inequality.
\end{abstract}

Keywords: Income Distribution; Kuznets' Curve; Economic Inequality

JEL Classification: D31; D33; E25; N30; P16

a Professor-pesquisador do Programa de Pós-Graduação em Economia na Faculdade de Economia da Universidade Federal Fluminense (UFF) e também professor-visitante no Programa de Pós-Graduação em Ciência Política da mesma universidade. Esteve por um ano como Visiting-Scholar no ILAS (Institute of Latin American Studies) da Universidade de Columbia, desenvolvendo projeto sobre o tema da desigualdade econômica. E-mail: fermatt1@ @otmail.com 


\section{Introdução}

O objetivo deste artigo é destacar a relevância que os trabalhos do economista bielorusso Simon Kuznets (notadamente seu artigo de 1955, intitulado "Economic Growth and Income Inequality", publicado na prestigiosa American Economic Review) ainda exibem até os dias de hoje, mostrando que sua contribuição teórica, sob diversos pontos de vista, tem estado presente nos momentos mais marcantes do debate sobre distribuição de renda nas décadas que se sucederam à publicação dos seus trabalhos, no auge dos tempos da Guerra Fria (Kuznets, 1953; 2010[1954]; 1955).

O trabalho de 1955 é mais conhecido pelo modelo que foi ali exposto e explicado pelo autor ${ }^{1}$. No entanto, entendemos que alguns aspectos importantes do processo de desenvolvimento econômico mencionados por Kuznets passaram despercebidos ou mereceram menos atenção do que deveriam por parte de seus mais variados intérpretes, conforme pretendemos mostrar nas seções deste artigo.

A leitura apressada ou interessada de alguns de seus comentadores deu azo a interpretações conservadoras, que procuraram tentar legitimar trajetórias de crescimento econômico marcadas por concentração de renda e de riqueza, tomando-as como meramente passageiras ou necessárias (entre outros motivos, por, supostamente, estimular o investimento) para a consolidação de processos de desenvolvimento econômico. Pior ainda, este tipo de abordagem tem sido esgrimido, tantas vezes, independentemente do momento histórico e do grau de desenvolvimento das forças produtivas do país em questão e de sua posição momentânea na divisão internacional do trabalho.

A partir de meados dos anos 1970 e, certamente, com mais nitidez a partir dos anos 1980, a realidade dos fatos, no que concerne à evolução dos perfis distributivos dos diferentes países capitalistas, bem como a disponibilidade de dados e informações estatísticas que pudessem descrevê-los, ao lado do desenvolvimento de técnicas de pesquisa e de tratamento das informações, colocaram em xeque as vertentes conservadoras das interpretações do "modelo" de Kuznets - e de sua suposta universalidade.

A maior parte do conteúdo do artigo de 1955 foi dedicada à formulação e descrição do modelo que ficaria conhecido, posteriormente, como a "Curva de Kuznets" pelos seus comentadores; no entanto, conforme vimos de afirmar, muitos aspectos importantes do processo de desenvolvimento econômico, conforme analisado pelo autor, merecem ser sublinhados aqui, com o intuito de mostrar a atualidade que persiste em seu trabalho para o debate sobre a evolução do perfil distributivo, ainda nos dias atuais. Estas questões serão discutidas ao longo do artigo e são elas, a saber: (a) a necessidade (e valorização intelectual) de ter acesso a novos dados e informações estatísticas, especialmente sobre rendas pessoais e familiares; (b) os aspectos políticos e institucionais que nortearam a atuação dos estados

\footnotetext{
${ }^{1}$ A primeira seção do artigo dedica-se, primordialmente, a explicar o referido modelo. Mas, adiantando aqui, trata-se de uma formulação que postula, com base na experiência de três países desenvolvidos, que o processo de crescimento econômico, em seus primeiros estágios, promove aumento da desigualdade de renda, a qual é revertida em favor de um perfil distributivo mais igualitário a partir de certo patamar do desenvolvimento econômico.
} 
nacionais e que atuaram (e ainda atuam) na conformação dos perfis distributivos ao longo dos processo de desenvolvimento econômico, tanto na época em que Kuznets formulava seus trabalhos pioneiros, quanto nas décadas seguintes e também nos momentos recentes segundo os condicionantes geopolíticos, econômicos e doutrinários de cada época -, mas que, em décadas passadas, mal puderam ser medidos de forma adequada, justamente por causa da precária disponibilidade ${ }^{2}$ de informações estatísticas ou de técnicas de tratamento de dados; (c) a peculiaridade (e, portanto, a indevida generalização do chamado "modelo" de Kuznets) dos países subdesenvolvidos - elemento muito mencionado por Kuznets, inclusive no seu artigo de 1954 (Kuznets, (2010[1954]), que precedeu o trabalho em que foi formulado seu famoso modelo ${ }^{3}$.

Antes de mais nada, é preciso lembrar que Kuznets foi um dos precursores da Teoria do Desenvolvimento (KUZNETS 1953; 2010[1954]; 1955), que surge dentro do contexto social, político e geopolítico do pós-segunda guerra ${ }^{4}$, atendendo a uma crescente demanda por estudos a respeito das formas pelas quais os países em desenvolvimento deveriam recuperar o atraso em que se encontravam em relação aos países capitalistas desenvolvidos (BASTOS e BRITTO, 2010).

Kuznets (1955) propôs um modelo de interpretação das mudanças estruturais ocorridas em economias que trilharam o caminho do desenvolvimento, descrevendo como esse processo promoveu alterações no perfil da distribuição pessoal da renda em três países: EUA, Reino Unido e Alemanha. Ao descrever as transformações estruturais relatadas pela passagem das sociedades agrícolas (atrasadas) para sociedades industriais (modernas ou avançadas), ele toma a questão distributiva para interpretar as metamorfoses estruturais ocorridas nas economias capitalistas.

$\mathrm{O}$ argumento que norteia o objetivo deste artigo reside na consideração segundo a qual os fatores apontados por Kuznets (1955) em seu artigo seminal para o surgimento da Teoria do Desenvolvimento também podem ser considerados elementos condutores do debate econômico sobre distribuição pessoal da renda que se encaminhou nas décadas

\footnotetext{
${ }^{2}$ Roine e Waldenström (2015) comentam que a disponibilidade maior de dados permite ampliar o debate sobre a desigualdade econômica e a distribuição de renda.

${ }^{3}$ Roine e Waldenström (2015) chama a atenção para a riqueza temática proposta pelos trabalhos de Kuznets, não se limitando à questão - desde logo muito importante - da relação entre crescimento e distribuição.

${ }^{4}$ Para delimitar o contexto em que surgiu e se desenvolveu a Teoria do Desenvolvimento enquanto um campo (ou disciplina) específico(a) da Teoria Econômica, Bastos e Britto (2010) arrolam diversas modificações ocorridas no âmbito político e também no cenário geopolítico do período. Os autores destacam que as reminiscências da Grande Depressão do entre guerras, bem como, obviamente, os próprios conflitos mundiais e seus desdobramentos estão entre as explicações para mudanças de paradigmas, como, por exemplo, a decadência da antiga hegemonia do Império Inglês e, com ela, a do pensamento liberal, substituído, na maior parte dos países, por experiências, de diversas matizes políticas, de intervenção do Estado na economia (basta lembrar de situações tão distintas politicamente como o New Deal, nos EUA, e a política econômica do nazismo, para não falar do surgimento e posterior desenvolvimento exitoso da URSS, que atingiria o pleno emprego muito antes dos países capitalistas desenvolvidos, compelindo os governos destes países a serem mais condescendentes com as demandas populares e de trabalhadores nos seus respectivos processos nacionais de desenvolvimento industrial).
} 
seguintes ${ }^{5}$. Desta forma, pode-se considerar que o trabalho de Kuznets (1955) também teve papel decisivo para colocar o tema da distribuição pessoal da renda como um campo de estudo específico da Teoria Econômica.

O contexto que deu ensejo à expansão da importância do tema da desigualdade teve seu debate viabilizado pela consolidação e organização de programas que buscaram construir séries, em perspectiva histórica, de dados de rendimentos, com refinada metodologia, para discutir a desigualdade entre os países e dentro deles. Destacam-se, nesse sentido, o surgimento, por exemplo, do projeto da Universidade do Texas (que envolve dezenas de pesquisadores de todo o mundo, provenientes de diversas áreas que, no Brasil, são denominadas de Ciências Sociais Aplicadas), intitulado University of Texas Inequality Project (UTIP), comandado pelo economista James Galbraith, como também a base de dados organizada pelo economista Thomas Piketty na Paris School of Economics (WID World Inequality Database), que também publica anualmente o World Inequality Report, devotado à apresentação de dados e à discussão da questão da desigualdade em dezenas de países, bem como a desigualdade mundial da renda. Da mesma forma, deve-se registrar a importância das estatísticas organizadas há décadas por Angus Maddison (Maddison World GDP Series), assim como das informações reunidas no Luxemburg Income Study (LIS) (e sua mais recente compilação, Luxemburg Wealth Study).

Além desta apresentação, este artigo é composto de mais três seções e das conclusões. Na primeira seção, apresentamos o trabalho de Kuznets de 1955, no qual ele formula a famosa interpretação da curva do "U invertido", postulando que a transição de sociedades atrasadas para sociedades modernas são atingidas, em um primeiro momento, por um aumento da desigualdade econômica, a qual, à medida que se consolida o processo de desenvolvimento econômico, tende a reverter-se em favor de uma distribuição pessoal da renda mais igualitária. Nessa primeira seção, também são feitas considerações em favor de uma recuperação de argumentos ponderados por Kuznets adicionalmente aos que ele utilizou especificamente para formular seu modelo. Na seção seguinte, mostramos que o cenário econômico e político se transforma significativamente a partir de 1980 e, com estas mudanças, altera-se também a trajetória dos indicadores de desigualdade da renda pessoal, que volta a subir, significando uma "reversão" da segunda parte da curva do "U invertido". $\mathrm{Na}$ terceira seção, pontuamos o que tem sido chamado, nos estudos sobre desigualdade econômica, de "o debate do 1\%", discussão que abre espaço não apenas para uma descrição do recente processo de concentração da renda, mas também para a necessidade de se investigar alguns aspectos político/institucionais. No final, apresentamos as conclusões.

\footnotetext{
${ }^{5}$ Piketty (2014) pontua que os trabalhos de Kuznets de 1953 e de 1955 representaram "a primeira tentativa de medir a desigualdade social em uma escala tão ambiciosa". Kuznets também foi o autor das primeiras contas nacionais americanas e das primeiras séries históricas sobre a desigualdade, conforme também lembra Piketty (2014) (rodapé 11 da p. 564).

${ }^{6}$ Também conhecida como o "sino de Kuznets", sendo que, na metade do lado direito do sino, a uma trajetória de queda da desigualdade segue-se um período de sua estabilidade.
} 


\section{Origem do Debate: 0 Caráter Pioneiro do Trabalho de Kuznets e o Contexto Peculiar do Pós-Segunda Guerra}

O trabalho clássico de Kuznets (1955) é um dos principais estudos fundadores da Teoria do Desenvolvimento surgida no pós-segunda-guerra. O contexto político, social e geopolítico daquele momento histórico delimitou as condições concretas para que o tema do Desenvolvimento Econômico se consolidasse como uma disciplina específica da chamada Ciência Econômica (BASTOS e BRITO, 2010). Kuzents (1955) procurou compreender e descrever o processo de crescimento econômico a partir de seus efeitos sobre a distribuição pessoal da renda.

$\mathrm{O}$ argumento que pretendemos defender é o de que o referido trabalho de Kuznets, além do papel exercido como precursor da Teoria do Desenvolvimento do pós-segunda guerra, acabaria representando também um marco para o debate sobre a desigualdade na distribuição de renda desfraldado a partir do pós-segunda guerra ${ }^{7}$, norteando o debate sobre distribuição pessoal da renda até os dias de hoje.

Em seu trabalho seminal, Kuznets (1955) toma dados de renda pessoal (renda familiar per capita $)^{8}$ da evolução dos rendimentos e de sua distribuição ao longo dos processos de industrialização em três países para os quais ele encontra dados disponíveis (Alemanha, Reino Unido e Estados Unidos ${ }^{9}$ ). No seu modelo, o autor divide a economia em dois setores (um atrasado - o setor agrícola; e outro, moderno - o setor industrial). Desta forma, ele procura descrever como se dá a trajetória do perfil distributivo em um país que paulatinamente vai deixando de ser pobre para tornar-se desenvolvido, à medida que as pessoas migram do setor mais atrasado para o mais moderno.

A curva de Kuznets também ficou conhecida como a curva do "U invertido", pois o autor postula (com base em evidências empíricas ${ }^{10}$ para os três países mencionados) que a desigualdade em países pobres é pequena e tende a aumentar à medida que estes países se desenvolvem (ou seja, à medida que a renda per capita cresce), até que atinge um valor de pico e depois começa a declinar quando a economia torna-se desenvolvida, estabilizandose em uma etapa seguinte.

\footnotetext{
${ }^{7}$ Therborn (2011) lembra que o tema da desigualdade surge como preocupação social durante o Iluminismo e, desde então, três pensadores se mostraram como propagadores de visões que se tornariam referências a respeito do tema. Dois deles, no século XIX: Alexis de Tocqueville, que apresentou uma interpretação de que haveria uma equalização no longo prazo; e Karl Marx, com uma visão oposta, segundo a qual, sob o Capitalismo, a desigualdade radical e a polarização seriam inevitáveis. O terceiro autor referencial para o debate, segundo o autor, foi Kuznets, com uma interpretação alcunhada de otimista por Thernborn.

${ }^{8}$ Conforme esclarece o autor, trata-se de dados ajustados para o tamanho médio das famílias, tomados segundo a renda bruta (ou seja, excluindo impostos e transferências) e também excluindo ganhos de capitais.

${ }^{9}$ No caso dos EUA, conforme salienta Piketty (2014), o autor se beneficia de fontes de dados que, no século XIX, não eram acessíveis para os autores do século XIX, quais sejam, as declarações de imposto de renda federal (instituído em 1913) e estimativas de renda nacional dos EUA, formuladas pelo próprio Kuznets em seu trabalho de 1953.

${ }^{10}$ Os dados referem-se ao período que se inicia no final do século XIX até anos próximos da publicação do artigo.
} 
Segundo a formulação de Kuznets, a migração das pessoas do setor atrasado para o setor moderno é impulsionada pela diferença de renda entre eles. A trajetória resultante desse movimento sobre a desigualdade total da economia depende: (1) dos níveis iniciais e das posteriores mudanças entre as diferenças intersetoriais de renda (estágio inicial e posterior evolução da diferença entre a renda média do setor atrasado e a do setor moderno); (2) dos níveis e das mudanças das diferenças intrasetoriais de desigualdade; (3) da proporção inicial (e ritmo) da população que migra do setor atrasado para o moderno.

Portanto, os elementos centrais do modelo de Kuznets são as diferenças de renda entre os setores e os respectivos graus de desigualdade dentro de cada um deles.

Ao que se propõe neste artigo, não é necessário discutir com detalhes os condicionantes e as limitações teóricas e metodológicas do modelo de Kuznets. O que se pretende, ao resgatar o artigo de Kuznets (1955), é ressaltar sua importância para iniciar o debate teórico e empírico em torno da questão distributiva. Nesta tarefa, pretende-se também contextualizar o momento histórico vivido pelo Capitalismo no momento em que suas formulações foram feitas, comparando-o com as diferentes etapas posteriormente vividas pelo processo de acumulação capitalista que, por sua vez, embasaram a evolução do debate sobre distribuição pessoal da renda nas décadas que se seguiram à publicação do referido estudo de Kuznets - conservando sua relevância até os dias atuais.

A experiência histórica mostra que, nos cerca de 25 anos após a Segunda Guerra Mundial, nos países desenvolvidos, houve uma redução da desigualdade pessoal de renda, o que parecia confirmar as hipóteses de Kuznets formuladas nos anos 1950.

O debate acerca da melhoria do perfil de distribuição de renda no pós-segunda guerra levou diversos autores ${ }^{11}$ a apontar que a redução da desigualdade foi muito mais obra das políticas sociais construídas no sistema de Welfare State (o que inclui não apenas as tradicionais políticas em educação e saúde, mas também políticas fiscal e tributária progressivas ${ }^{12}$ ), do que pela interação das forças de oferta e de demanda nos respectivos mercados de trabalho nacionais. O sistema de Welfare State, marca do período, veio junto a uma política de pleno emprego, expansão dos gastos públicos e finanças nacionais de movimentos controlados e "a serviço da produção"13 (Plihon, 1996). O ciclo virtuoso entre investimento público e investimento privado estava, em grande medida, viabilizado pelo fato de que os mercados financeiros eram regulamentados e os fluxos internacionais de capital financeiro, contidos (Belluzzo, 2016; Mattos, 2009). A política tributária era ativa

\footnotetext{
${ }^{11}$ Por exemplo: Piketty (2014); Therborn (2011); Streeck (2018); Belluzzo (2016).

12 O próprio Kuznets (1955) reconhece que, se, ao invés de tomar as rendas brutas, tivesse tido acesso a informações oficiais sobre rendimentos após a incidência de impostos e de transferências (rendas líquidas), sua formulação sobre a redução da desigualdade revelar-se-ia ainda mais consistente.

${ }^{13}$ Durante os chamados Anos Dourados do Capitalismo, a institucionalidade financeira internacional estava montada de tal forma que as finanças nacionais estavam "a serviço da produção" (Plihon, 1996), revitalizando a acumulação de capital especialmente via financiamento dos investimentos destinados à ampliação da capacidade produtiva instalada (e do emprego, por conseguinte). A partir do desmonte da institucionalidade definida em Bretton Woods, as finanças foram gradativamente se autonomizando da esfera produtiva e o padrão de acumulação de capital foi se alterando em direção à "financeirização da riqueza", nas palavras de Chesnais (1996; p. 36).
} 
e progressiva (a carga tributária cresceu e repousou especialmente em impostos sobre a renda e o patrimônio, conforme mostraram, pelo menos, Piketty (2014) e Dedecca (2012)). Os gastos públicos também eram progressivos, diminuindo, na prática, a desigualdade econômica, quer seja pelas transferências monetárias feitas aos mais pobres, quer seja pela expansão da oferta de bens e serviços públicos (Mattos, 2009).

O trabalho elaborado por Kuznets (1955) abre espaço para avaliar fatores que vão além dos elementos relacionados ao dinamismo do funcionamento do mercado de trabalho, a principal base da formulação do modelo que ficaria conhecido pela literatura como a "curva de Kuznets"14. Deve-se ressaltar, contudo - e este é um ponto importante em nossa argumentação - que, no referido artigo, o próprio autor reconhece a necessidade de que a questão distributiva seja discutida de uma maneira mais ampla do que a que ele próprio desenvolveu, consideradas as limitações, então existentes, de disponibilidade de dados e informações estatísticas. O seu trabalho é mais conhecido pela análise do comportamento do mercado de trabalho e dos perfis de rendas ali geradas. No entanto, outros elementos por ele arrolados como também determinantes da trajetória das desigualdades de renda nos países acabariam surgindo em trabalhos futuros de outros autores que também tratariam do tema da distribuição pessoal da renda.

Estes outros elementos são mencionados quando ele passa a analisar os aspectos que levam à redução da desigualdade econômica do conjunto do sistema (a parte descendente da curva de Kuznets). Ilustrando seus argumentos com simulações numéricas hipotéticas, Kuznets (1955) postula que, com a "crescente industrialização", o crescimento do peso do setor moderno promove o aumento da renda do conjunto da economia; nesse contexto, uma composição de fatores como a redução da diferença intersetorial de renda, a redução gradativa do ritmo de migração (justamente porque o setor agrícola torna-se cada vez menor) e também uma eventual redução da desigualdade existente dentro do setor moderno se somam para promover a redução do "range" (diferença) da renda apropriada entre os quintis extremos - ou seja, uma redução da desigualdade.

A seguir, o autor argumenta que, quando a sociedade se urbaniza (justamente em consequência da própria industrialização/modernização da economia e eventuais efeitos sobre demandas democráticas), surgem fatores sociais e políticos - mencionados mas pouco detalhados por ele - que também afetariam o perfil distributivo do conjunto do sistema, ou o que ele chama de "total income distribution" (pág. 8).

Ele destaca essas questões políticas e institucionais notadamente quando opera uma comparação entre o que ocorreu com os três países cujos dados foram avaliados mais atentamente, aos parcos (mas elucidativos) dados já então disponíveis referentes a países subdesenvolvidos ainda em meados do século XX. O autor havia comentado, quando analisou o processo de modernização nos países então em 1955 já desenvolvidos, que forças políticas - muitas delas decorrentes da própria maturação do processo de modernização/industrialização e urbanização - tiveram o papel de promover maior

\footnotetext{
${ }^{14} \mathrm{O}$ próprio Kuznets não usa esses termos; limita-se a apresentar seu exercício de dois setores acima mencionado.
} 
participação dos estratos mais baixos de renda no conjunto da renda nacional, revertendo o processo inicial de ampliação da desigualdade global de rendimentos que surge na economia quando da transição de pessoas do setor mais atrasado para o mais moderno ${ }^{15}$.

O contexto em que Kuznets redigiu seu trabalho clássico era de prosperidade econômica e social, tanto nos EUA, como na Europa Ocidental recém-reconstruída e então já em processo de acelerado crescimento. O debate específico sobre distribuição de renda, porém, ficaria submerso por algumas décadas, por motivos que foram muito bem refletidos por John K. Galbraith (1958), em sua interpretação original - e que também se tornaria clássica - sobre a natureza das transformações econômicas e sociais da "Sociedade Afluente". Tomando como referência os EUA, Galbraith (1958) sustenta que a própria prosperidade da "Sociedade Afluente" teria sido um dos fatores para que a desigualdade, enquanto tema de interesse acadêmico e político, não tivesse o protagonismo que, segundo ele, deveria ter, pois a prosperidade não eliminara o problema da iniquidade na sociedade americana. Segundo postula Galbraith (1958), enquanto a renda em geral está subindo, as pessoas não estariam muito preocupadas com "um ou outro milionário de Nova Iorque ou do Texas" $" 16$.

A partir do final dos anos 1970, porém, as economias desenvolvidas passam a exibir taxas de crescimento menores do que nos Anos Dourados, o que, entre outros fatores, culminaria com mudanças políticas que levariam à ascensão de Thatcher e de Reagan ao poder (em 1979 e em 1980, respectivamente) e a consequentes mudanças nos principais parâmetros de elaboração das políticas econômicas dos países desenvolvidos, em contexto de mudança no cenário econômico/financeiro internacional.

Na seção seguinte, procuramos mostrar como o debate sobre a questão distributiva toma novos rumos e relevância, à medida que os dados passam a indicar uma "reversão" da chamada "curva de Kuznets", ou seja, uma nova ascensão da desigualdade. Procura-se também mostrar que a contribuição seminal de Kuznets, sob diversos aspectos, ainda

\footnotetext{
${ }^{15}$ De todo modo, é importante ponderar que ele, no artigo de 1955, em algumas passagens, alerta que seu "modelo" não deveria servir para generalizações, notadamente quando se debruça sobre as especificidades de países subdesenvolvidos. No acima citado artigo de 1954 (Kuznets, 2010[1954]), ele já adiantava algumas reflexões sobre o tema, como se percebe nas seguintes passagens: "Se a intenção for enfatizar as semelhanças e diferenças entre características básicas do processo de adoção do sistema industrial - para países de diferentes tamanhos, heranças históricas e cronologias no processo de industrialização -, necessitaremos, certamente, de uma grande variedade de estudos de nações" (p. 179). Logo em seguida: "É a partir desses estudos de períodos prolongados - com ênfase na interconexão das tendências seculares na população, no nível e na estrutura econômica, nas instituições políticas e sociais internas e no cenário mundial - que esperamos tirar conclusões testáveis que possam ser úteis para a compreensão e o tratamento dos problemas de crescimento econômico dos países subdesenvolvidos" (p. 179). Ou seja, em poucas palavras, ele, desde pelo menos o artigo de 1954, já postulava que cada país deveria encontrar o seu caminho.

${ }^{16}$ A rigor, vale lembrar que, nos anos 1960, notadamente sob a presidência de Lyndon Johnson, o conjunto de políticas sociais adotado sob o âmbito da "Grande Sociedade", nos EUA, tinha no programa de "Guerra à Pobreza" seu principal componente, revelando maior preocupação com a pobreza do que, mais exatamente, com um programa sistemático (e, portanto, mais abrangente e estrutural) de enfrentamento da desigualdade econômica e social - embora, conforme lembra o próprio Galbraith (1958), este fosse um problema grave na sociedade americana naquele período.
} 
continuaria sendo referência para os parâmetros pelos quais se desdobraria o debate sobre distribuição de renda.

\section{A "Reversão" da Curva de Kuznets e os Novos Desdobramentos do Debate Distributivo}

A partir do início dos anos 1980, na maioria dos países capitalistas desenvolvidos ocorreu aumento da desigualdade, colocando em questão a validade do modelo de Kuznets. O impacto do trabalho de Kuznets na academia e nos meios políticos (e a realidade econômica vigente até os anos 1970) levou, durante algumas décadas, a uma certa letargia no interesse por estudos sobre desigualdade. Para muitos autores, o tema não deveria ser motivo de preocupação dos economistas, seja porque, supostamente, a desigualdade seria um fenômeno estável ao longo do tempo, ou, quando não, a concentração da renda seria algo positivo por estimular investimentos produtivos (e, portanto, prosperidade econômica e social para o conjunto do sistema) por parte dos inicialmente beneficiários da própria expansão da desigualdade. A referida visão conservadora pode ser resumida pelo aforismo de Aaron (1978; p. 2), segundo o qual "watching trends in income inequality is like watching the grass grow". Desta forma, a realidade exibida pelo comportamento da trajetória de indicadores de desigualdade, a partir do final dos anos 1970 e, de forma mais evidente (e nacionalmente abrangente), a partir dos anos 1980, colocava em questão a essência da curva de Kuznets e eventuais formas conservadoras de interpretação da mesma (embora ele jamais tenha dito que seu modelo poderia ser generalizado para todos os momentos e países).

O gráfico I, portanto, revela o equívoco da pensata de Aaron, ilustrando, para países desenvolvidos selecionados, a trajetória da desigualdade da renda pessoal durante o século XX e a primeira década do atual século, mostrando não somente o movimento de equalização ocorrido desde o início do século (no qual se contextualizou a produção do modelo de Kuznets), como também a generalizada reversão ocorrida a partir de 1980. 


\section{Gráfico I: A Parcela do Décimo Superior: Europa e EUA}

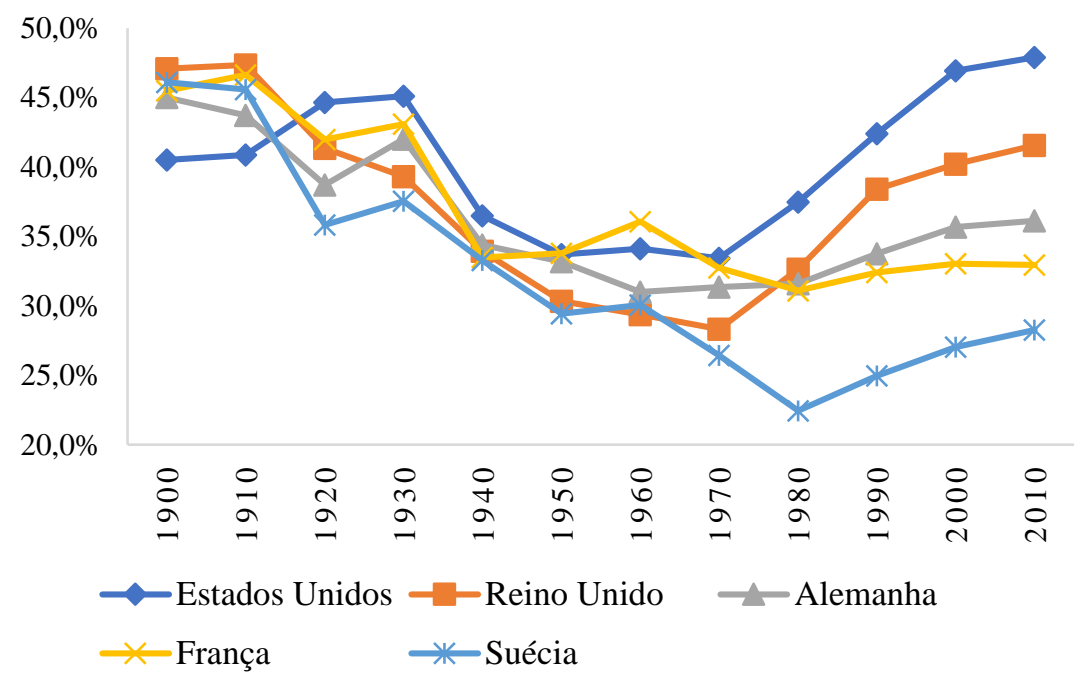

Fonte: Elaboração própria a partir de Apêndice disponibilizado em Piketty (2014).

O desenvolvimento de novas técnicas para a ampliação das bases de dados, nas décadas seguintes, abriu espaço não somente para uma averiguação mais acurada do fenômeno descrito por Kuznets, como também para compreender a posterior reversão das trajetórias nacionais dos indicadores de desigualdade; ademais, a diversificação e consolidação das bases de dados permitiram avaliar a desigualdade de uma forma mais ampla, procurando abarcar não apenas as rendas do trabalho, mas também as provenientes de outras fontes. Esta, aliás, era uma preocupação revelada por Kuznets (1955) em seu trabalho clássico, no qual chamava a atenção para a necessidade de novas e mais amplas bases de dados, para dar conta da árdua tarefa de analisar a complexidade envolvida na transformação econômica e seus efeitos distributivos ${ }^{17}$.

O trabalho econométrico apresentado por Galbraith e Kum (2002) mostra evidências, segundo os autores, de que a curva de Kuznets de fato havia se verificado em vários países durante o relativamente longo período estudado pelo trabalho clássico. Porém, a partir de 1980, segundo observam os autores, em quase todos os países ocorre um crescimento da desigualdade, independentemente do nível prévio de renda per capita e da trajetória e dimensão do crescimento da renda de cada experiência nacional.

A contribuição central dos autores (que se contrapõe às interpretações do main stream) é sustentar o argumento segundo o qual, dada a dimensão e a generalização da ampliação das desigualdades dentro dos países ocorrida a partir de 1980, seria adequado

\footnotetext{
${ }^{17}$ No final do artigo, ele mesmo reconhece a relativa precariedade das informações com as quais trabalhou para redigir seu trabalho: "The paper is perhaps 5 per cent empirical information and 95 per cent speculation" (pág. 26).
} 
postular que, dada a magnitude e generalização daquele fenômeno, o mesmo somente poderia estar condicionado a mudanças ocorridas na formatação da ordem financeira internacional. Desta forma, os autores ponderam que apenas medidas tomadas no âmbito nacional não seriam suficientes para enfrentar o problema em países específicos. Interessante também registrar esse aspecto mencionado, pois de fato estudos de James Galbraith $^{18}$ (anteriores e também posteriores a esse, em coautoria com Kum) sempre procuraram mostrar fatores macroeconômicos, bem como aspectos de política internacional, para explicar as trajetórias e os novos quadros de desigualdade. Nesse sentido, as pesquisas de James Galbraith ${ }^{19}$ também exibem um caráter destacado no debate econômico sobre a desigualdade de renda, notadamente por chamarem a atenção para a necessidade de superar, no âmbito da Teoria Econômica, o paradigma microeconômico que baseia explicações acerca de mudanças de perfis distributivos a partir dos movimentos das forças de oferta e demanda nos mercados de trabalho e dos "prêmios" associados à qualificação profissional da mão de obra. A tradição keynesiana dos trabalhos de James Galbraith tomam as mudanças ocorridas nos mercados de trabalho como resultados e não como causas das transformações econômicas mais significativas, entre elas a da distribuição pessoal da renda.

A mudança do cenário econômico e político, a partir dos anos 1980, provocou, segundo Atkinson $(1997)^{20}$, a retomada do interesse acadêmico no tema ${ }^{21}$. As mudanças na realidade política e a crescente disponibilidade de indicadores econômicos, em especial os de desigualdade econômica, levam o autor a chamar a atenção para a necessidade e relevância de se estudar o tema sob a perspectiva da distribuição pessoal da renda ${ }^{22}$,

\footnotetext{
${ }^{18}$ Ver, pelo menos: Galbraith (2018; 2012b; 2009; 2002; 1998).

19 Já em Galbraith (1998), o autor chamava a atenção para a necessidade de se analisar a questão distributiva fugindo dos parâmetros do "pensamento convencional", incorporando aspectos macroeconômicos keynesianos ao instrumental analítico que se dedicava a discutir a questão distributiva, e revelando a inadequação de interpretações neoclássicas baseadas no funcionamento das "forças de oferta e demanda" do mercado de trabalho para interpretar a expansão da desigualdade que já se mostrava evidente desde o início dos anos 1980. Nas obras posteriores, o autor incorporaria também fatores geopolíticos, aspectos da ordem financeira internacional e também elementos relacionados à concentração de poder e de fragilidades da Democracia para explicar a escalada da desigualdade econômica e social, relatando experiências em vários países, como por exemplo em Galbraith (2012 a).

${ }^{20} \mathrm{O}$ título (e o conteúdo) do referido artigo é o mesmo do discurso do autor, proferido quando assume a Presidência da Royal Economic Society.

${ }^{21} \mathrm{O}$ autor afirma que "The title of this Presidential Address is chosen to highlight the way in which the subject of income distribution has in the past been marginalized. For much of this century, it has been very much out in the cold. There are signs that in the 1990s it is being welcomed back, and I shall be referring to recent research, but I would like to use this occasion to give further impetus to the re-incorporation of income distribution into the main body of economic analysis" (pág. 297).

${ }^{22}$ Conforme explica Atkinson (1997), o cenário e a percepção acerca da trajetória da desigualdade se alteraram: "As we now know, income inequality did not continue to fall". No referido trabalho, Atkinson (1997), tomando como referência o trabalho de Kuznets (1955), destaca que o crescimento da desigualdade foi generalizado, tendo sido especialmente expressivo no Reino Unido, cujos resultados não encontravam paralelo histórico entre os países comparados. O estudo, portanto, contextualiza as mudanças ocorridas e, dado o grau com que ocorreram estas alterações, chama a atenção para a necessidade de se retomar estudos sobre a desigualdade e,
} 
conforme havia feito Kuznets nos estudos dos anos 1950, e contrariamente ao que estava posto pela tradição de autores clássicos, como David Ricardo, por exemplo, de buscar compreender a dinâmica econômica a partir de estudos sobre a repartição funcional da renda.

No referido artigo (ATKINSON, 1997), além de exortar seus pares à "reincorporação" do tema da distribuição de renda entre os principais pontos das agendas acadêmicas de pesquisas da Teoria Econômica, o autor alerta para os eventuais enganos em que se poderia incorrer supondo que a curva do " $U$ invertido" representasse uma regra geral $^{23}$ para os países e, mais do que isso, algo perene, em cada um deles, uma vez inicialmente estabelecida a trajetória de redução da desigualdade pessoal da renda. $\mathrm{O}$ próprio Kuznets (1955) havia chamado atenção para o possível equívoco de se generalizar o ocorrido no pós-guerra para o futuro mais distante e também para países nãodesenvolvidos. Em artigo que fora escrito em 1954, mas traduzido em versão para Kuznets (2010[1954]), o próprio autor já ponderava que "tanto a posição econômica relativa como a absoluta, assim como o padrão geral da história dos países hoje desenvolvidos em sua fase pré-industrial, foram radicalmente diferentes da posição econômica e da herança histórica imediata dos países subdesenvolvidos do presente. Daí não ser nada seguro projetar aspectos econômicos ou demográficos das séries estatísticas mais antigas dos países desenvolvidos para níveis atuais e futuros dos subdesenvolvidos" (KUZNETS (2010[1954]; p. 177). Preocupações e ponderações deste mesmo jaez também seriam feitas no artigo de 1955, revelando o açodamento dos que, durante diversas décadas seguintes, apregoaram (ou "preferiram" apregoar?) que bastaria ocorrer crescimento econômico para que os perfis distributivos se amoldassem a um estágio menos desigual.

em especial, para a relevância e urgência de se discutir o aspecto pessoal da distribuição de renda, fazendo coro com estudo clássico citado e resgatado por ele, de autoria de Dalton (1920), no qual aquele autor pontuava que "distribution as between persons" was "a problem of more direct and obvious interest", em comparação com a distribuição dos fatores de produção, como era mais encontradiço nos estudos clássicos de Economia Política. ${ }^{23}$ Ainda na versão traduzida de 2010, Kuznets (2010[1954]) pondera, a seguir da citação acima mencionada, o papel que instituições e fatores políticos (ou seja, não apenas o "livre mercado" de que tantos de seus supostamente fiéis seguidores falariam, nas décadas posteriores) tiveram, nos países atualmente desenvolvidos, e deveriam ter, nos que gostariam de trilhar o mesmo caminho de prosperidade: "Há hoje em dia grandes diferenças de níveis econômicos, estrutura social e, presumo, padrões demográficos entre os países que ocupam o topo da classificação como desenvolvidos e os mais subdesenvolvidos. Esse distanciamento é, em si mesmo, um fator importante na determinação de políticas e perspectivas de crescimento econômico nos países subdesenvolvidos. Mas deveria inibir extrapolações fáceis a partir de cortes temporais" (p. 177/178). No artigo de 1955, Kuznets vai na mesma toada, alertando para as diferenças entre os países desenvolvidos e os subdesenvolvidos, no que ele está, na prática, alertando para o fato de que a "generalização" de seu modelo não é algo que se devesse fazer, sem as devidas mediações. Uma das passagens que expressa essas ponderações está registrada em seção em que compara países desenvolvidos com subdesenvolvidos - e se relaciona a questões político/histórico/institucionais: "This comparison is for income before direct taxes and excluding free benefits from governments. Since burden and progressivity of direct taxes are much greater in developed countries, and since it is in the latter that substantial volumes of free economic assistance are extended to the lower-income groups, a comparison in terms of income net of direct taxes and including government benefits would only accentuate the wider inequality of income distributions in the underdevelopment countires" (Kuznets, 1955; p. 21). 
A argumentação central de Atkinson (1997) procura ressaltar dois aspectos importantes do cenário econômico daquele momento (meados dos anos 90), uma vez já claramente materializados os efeitos, sobre os perfis de distribuição de renda, das mudanças iniciadas a partir do início dos anos 1980: (a) o fato de que a mudança do perfil da distribuição pessoal da renda representava uma deterioração das condições de vida das famílias e um aumento sistêmico da desigualdade econômica nas sociedades capitalistas ocidentais, algo que contrastava com o recém terminado período de prosperidade e esperanças sociais construído concomitantemente com o surgimento (ou ampliação) do Welfare State $^{24}$, sistema que tinha no próprio autor um dos principais articuladores e entusiastas; (b) o fato de que a participação da renda do trabalho no conjunto da renda das famílias estava em queda, o que abria dois flancos de avaliação que, conforme pretendemos mostrar a seguir, também seriam aprofundados em estudos nas décadas posteriores: a necessidade de se investigar a natureza das rendas provenientes do capital ${ }^{25}$, bem como os rendimentos oriundos das políticas sociais, estas fortemente afetadas pela dinâmica da Política $^{26}$ e também pela forma como as instituições passariam a moldar a Democracia e, em especial, as representações parlamentares nos diferentes países.

Não por acaso, um de seus principais discípulos, o economista francês Thomas Piketty, em obras publicadas em anos posteriores, debruçou-se na análise dos rendimentos do capital e seu impacto nos orçamentos familiares e/ou nas rendas pessoais; ademais, Piketty também chamaria atenção para o desenho adquirido pelas políticas sociais (o que inclui, obviamente - e com ênfase -, a política tributária e seus desdobramentos). Os principais elementos adiantados em Atkinson (1997) estariam presentes no "debate sobre

\footnotetext{
${ }^{24}$ O que chama a atenção, nos anos 1980, notadamente no que se refere aos dados vigentes no final da década, é que o Indice de Gini calculado pós incidência de taxas e transferências parecia ter crescido mais do que o Gini da renda primária (bruta), situação que contrasta justamente com aquilo que havia sido uma das marcas do surgimento e posterior fortalecimento dos sistemas nacionais de Welfare State (KERSTENETZKY, 2012). Isso já mostrava, em meados dos anos 1990, um relativo desmonte das políticas públicas que haviam sido construídas no pós-guerra, entre as quais a progressividade da estrutura tributária e da política fiscal, bem como (isso é muito importante) a flexibilização da regulação das relações de trabalho ocorridas a partir dos anos 1980 (MATTOS, 2009).

${ }^{25}$ Notadamente os rendimentos provenientes da miríade de ativos financeiros criados no bojo do processo de desregulamentação da ordem financeira internacional, como também diversas origens e formas de rendimentos provenientes do capital produtivo e também decorrentes de posse de ativos como patentes, e outros direitos de propriedade e de exploração de conhecimentos tecnológicos, ganhos com ações etc. De todo modo, também e ainda do ponto de vista dos salários, deve-se destacar a proeminência de estudos sobre alterações nos mecanismos de remuneração dos altos executivos - os supersalários, conforme veremos na seção seguinte.

${ }^{26}$ Atkinson (1997): "My principal purpose here has been to argue that the economic analysis of the distribution of income is in need of further development before we can hope to give a definitive answer to the questions in which the ordinary person is interested - such as what determines the extent of inequality and why has inequality increased? This does not mean that current economic theory has nothing to contribute. It certainly offers insights into parts of the story, but what is required is for the different elements to be brought together. We need an overall framework, both conceptual and empirical, within which to fit the different mechanisms. The skill shift explanation for wage differentials is valuable, but it is only part of the story. The labour market cannot be seen as totally independent from the capital market. Both economic and political economy explanations have their place".
} 
o 1\% do topo", que reúne as discussões sobre o papel dos rendimentos do capital e também de fatores "não estritamente econômicos" na conformação dos perfis distributivos das sociedades do século XXI. Esta é a tarefa a que se dedica a próxima seção.

\section{A Questão do 1\% Mais Rico: Aspectos Econômicos e Políticos da Natureza da Desigualdade Crescente dos Anos 2000}

A ascensão da temática do $1 \%$ do topo da distribuição como uma das preocupações centrais do debate sobre distribuição pessoal da renda no século XXI provém de diversos motivos. O primeiro deles - e mais óbvio - reside no fato de que a parcela da renda total apropriada por este estrato vem crescendo ao longo das últimas décadas e de forma até mais intensa nos anos $2000^{27}$, especialmente nos países de origem anglo-saxônica. Os dados da tabela 1 revelam que, entre 1960 e 2010, a participação do $1 \%$ mais rico na renda nacional somente não aumentou na França, dentre os países selecionados. Da mesma forma, a parcela apropriada pelo $0,1 \%$ (os muito ricos de cada país) vem exibindo uma trajetória de crescimento, desde os anos 1980, muitas vezes inclusive acima do crescimento da parcela que agrega o próprio 1\%. Há sinais, inclusive, de que, depois da crise deflagrada em 2008, a concentração no topo tenha até mesmo continuado a se expandir ${ }^{28}$.

Desta maneira, o mero fato de que este estrato (e suas subdivisões ainda menores) absorver parcela crescente da renda nacional na quase totalidade dos países capitalistas desenvolvidos torna o seu estudo relevante e até mesmo imperioso. A ampliação das parcelas absorvidas pelo $1 \%$ mais rico significa redução na parcela dos demais estratos, de tal forma que, mesmo indicadores sintéticos pouco sensíveis a mudanças ocorridas nos extremos da distribuição, como é o caso, por exemplo, do índice de Gini, acabam exibindo alterações indicativas de aumento da desigualdade na distribuição de renda. Ademais, conforme mostram diversos estudos recentes (PIKETTY, 2014; KEISTER, 2014; ATKINSON e BOURGUIGNON, 2015; ATKINSON, PIKETTY, SAEZ, 2011), a composição dos rendimentos do $1 \%$ do topo, notadamente em suas subdivisões ainda menores, revelam alterações expressivas na contribuição de rendimentos do trabalho e de rendimentos do capital produtivo e/ou advindos de ativos (financeiros ou não) ${ }^{29}$ cuja compreensão exige que aos aspectos "estritamente econômicos" sejam associados fatores políticos e institucionais.

\footnotetext{
${ }^{27}$ Dados de Piketty e Saez (2013) sobre os EUA são reveladores do papel do $1 \%$ mais rico nos tempos recentes. Os autores mostram que, entre 1993 e 2000 (período de 4,0\% de crescimento real do PIB ao ano, em média), este estrato absorveu $45 \%$ do total de crescimento da renda do país. Esta parcela já elevada aumentaria para $65 \%$ entre 2002 e 2007 , período em que o crescimento foi menor (3,0\% ao ano, em média).

${ }^{28}$ A participação do 0,1\% mais rico, na França, por exemplo, atinge seu ápice em 2010.

${ }^{29}$ Sobre a natureza e perfil dos rendimentos do $1 \%$ do topo, Piketty (2014) ressalta que, na "base" desse restrito grupo de pessoas, o peso dos salários (no caso, dos "supersalários" de CEOs, tanto de grandes conglomerados empresariais como também de instituições do mercado financeiro) ainda é predominante (em relação a rendimentos do capital), perdendo espaço para rendimentos provenientes do capital à medida que se "caminha" para subdivisões ainda menores do percentil mais alto (ou seja, nos estratos de $0,5 \%$, ou mesmo do $0,1 \%$ ou $0,01 \%$ mais altos).
} 


\section{Tabela 1: Evolução da Participação da Renda no Topo da Distribuição}

\begin{tabular}{c|c|c|c|c|c|c|c}
\hline \multicolumn{6}{c}{ Parcela da renda total apropriada pelo 1\% mais alto } \\
\hline Anos & França & Reino Unido & EUA & Canada & Suécia & Itália \\
\hline 1960 & 9,7 & 8,9 & 8,4 & 9,8 & 6,8 & n.d. \\
\hline 1970 & 8,3 & 7,1 & 7,8 & 9,0 & 6,2 & 7,5 \\
\hline 1980 & 7,6 & 6,3 & 8,2 & 8,1 & 4,1 & 6,9 \\
\hline 1990 & 8,2 & 9,8 & 13,0 & 9,4 & 4,4 & 7,8 \\
\hline 2000 & 7,6 & 12,7 & 16,5 & 13,6 & 6,0 & 9,1 \\
\hline 2006 & 8,9 & 14,8 & 18,1 & 13,7 & 6,6 & 9,7 \\
\hline 2010 & 8,8 & 14,7 & 17,4 & 12,3 & 6,9 & 9,4 \\
\hline Parcela da renda total apropriada pelo 0,1\% mais alto \\
\hline Anos & França & Reino Unido & EUA & Canada & Suécia & Itália \\
\hline 1960 & 2,5 & 2,5 & 2,1 & 2,5 & 1,6 & n.d. \\
\hline 1970 & 2,0 & 1,6 & 1,9 & 2,1 & 1,3 & 1,8 \\
\hline 1980 & 1,9 & 1,5 & 2,2 & 2,0 & 0,7 & 1,7 \\
\hline 1990 & 2,2 & 3,1 & 4,9 & 3,0 & 1,0 & 1,9 \\
\hline 2000 & 1,9 & 4,6 & 7,1 & 5,2 & 1,9 & 2,5 \\
\hline 2006 & 2,2 & 5,6 & 8,0 & 5,4 & 2,2 & 2,7 \\
\hline 2010 & 2,6 & 5,6 & 7,5 & 4,4 & 2,2 & 2,7 \\
\hline \multicolumn{7}{c}{}
\end{tabular}

Relação entre $0,1 \%$ e $1 \%$ mais alto

\begin{tabular}{c|c|c|c|c|c|c}
\hline Anos & França & Reino Unido & EUA & Canada & Suécia & Itália \\
\hline 1960 & 0,25 & 0,28 & 0,25 & 0,26 & 0,24 & n.d. \\
\hline 1970 & 0,24 & 0,23 & 0,25 & 0,23 & 0,21 & 0,24 \\
\hline 1980 & 0,25 & 0,24 & 0,27 & 0,25 & 0,17 & 0,25 \\
\hline 1990 & 0,27 & 0,32 & 0,38 & 0,32 & 0,23 & 0,24 \\
\hline 2000 & 0,25 & 0,37 & 0,43 & 0,38 & 0,32 & 0,27 \\
\hline 2006 & 0,25 & 0,38 & 0,44 & 0,39 & 0,33 & 0,28 \\
\hline 2010 & 0,30 & 0,38 & 0,43 & 0,36 & 0,32 & 0,29 \\
\hline \hline
\end{tabular}

Fonte: Elaboração própria a partir de Atkinson, Piketty e Saez (2010) (até 2006).

A partir daí, dados coletados no site do livro de Piketty (2014). (*) dados do Reino Unido: o de 1980 é, na verdade, de 1981; o de 1990 é de 1993. Renda antes da incidência de impostos e excluindo ganhos de capital Países e anos selecionados

A já mencionada mudança ocorrida no cenário político, a partir dos anos 1980, promoveu um progressivo desmonte dos mecanismos que haviam sustentado o padrão de acumulação dos anos do pós-segunda guerra (STREECK, 2018). A flexibilização dos mercados de trabalho e a desregulamentação dos mercados financeiros impulsionaram mudanças importantes no padrão de acumulação capitalista, que passaria a repousar cada vez mais na valorização financeira do capital, em detrimento dos investimentos produtivos (CHESNAIS, 1996; BELLUZZO, 1996; 2016). 
O rentismo ${ }^{30}$ resistiu mesmo aos movimentos de quedas de juros reais nas décadas seguintes, da mesma forma que a precariedade dos mercados de trabalho persistia mesmo nos momentos de retomada do nível da atividade econômica. A precariedade dos empregos criados deriva da perda de poder de barganha dos trabalhadores na disputa pelo excedente (KRISTAL, 2010). A expressão do rentismo se nota também na presença crescente de rendimentos provenientes de uma diversificada gama de "produtos financeiros" nos orçamentos familiares e nos balanços das empresas do setor produtivo. No âmbito familiar, a queda da presença dos salários pode ser "compensada" pelos rendimentos provenientes da posse de ativos financeiros (PIKETTY, 2014), ou pela expansão do crédito em momentos específicos (STREECK, 2018).

Este processo de mudança do perfil dos rendimentos, porém, tem se manifestado de forma desigual, impulsionando a concentração da renda e da riqueza no topo. A natureza e a "velocidade" da desigualdade são diferentes, nos anos 2000, das que ocorreram a partir dos anos 1980 (notadamente nos casos dos países de origem anglo-saxônica), o que explica o aumento recente da preocupação de pesquisadores com a questão das rendas do topo da distribuição (o debate do 1\% mais rico"). Esse debate é deflagrado pelas obras de Piketty (2001; 2003), em estudos sobre a França que retomam uma tradição que também vinha de pesquisas desenvolvidas ainda nos anos 1950 por Kuznets $(1953)^{31}$, mas que ainda não haviam rendido frutos práticos devido à indisponibilidade de dados (ROINE e WALDENSTRÖM, 2015), informações e técnicas de captação de dados naquele momento. Atkinson, Piketty e Saez (2011) revelam a necessidade de se superar o uso de registros de pesquisas domiciliares (algo que fora prenunciado por Kuznets ${ }^{32}$ ) e completá-los com

\footnotetext{
${ }^{30} \mathrm{Na}$ definição de Pikettty (2014), a sociedade patrimonial e rentista se define como aquela em que "a renda vinda do capital herdado ultrapasse a renda do trabalho no topo da hierarquia social". O autor menciona diversos aspectos que merecem aqui ser citados. Em primeiro lugar, a sociedade tende a ser tão mais caracterizada pelo rentismo quanto mais o crescimento da taxa de retorno do capital se mantiver acima de crescimento da renda nacional, notadamente se isso ocorrer por um tempo prolongado (como é o caso nas últimas décadas na maior parte dos países capitalistas) (pág. 400). E isso é tão mais verdade à medida que a participação do capital na renda nacional (denotando alta e progressiva piora) for alta e crescente ao longo do tempo (p. 32), ainda mais se o peso do capital herdado for relevante ou crescente dentro do conjunto da riqueza (p.400). Estas observações, captadas em diversas passagens do livro de Piketty (2014), nos permitem concluir que, além de fatores "estritamente econômicos", há também elementos políticos no contexto de um sociedade que se torna cada vez mais "patrimonial ou rentista", uma vez que, por exemplo, regras relacionadas à tributação dos altos rendimentos, sejam eles provenientes do trabalho ou do capital (em sua diversas modalidades), bem como a importante (e, muitas vezes, pouco destacada por autores que se debruçam no tema da desigualdade econômica) questão da tributação das heranças, são todas definidas nos âmbitos dos respectivos parlamentos nacionais ou no jogo de forças políticas que levam à constituição dos Poderes Executivos dos respectivos países.

31 Keister (2014) lembra que a generalização do uso de registros de imposto de renda é uma marca da sofisticação do debate sobre a questão distributiva, mostrando a relevância de se discutir não apenas a trajetória e a composição da renda, como também da riqueza (em todos os países capitalistas ainda mais concentrada do que a renda) e de seus efeitos sobre os rendimentos totais das famílias (entendendo rendimentos totais como a soma dos rendimentos provenientes do trabalho com rendimentos provenientes de outras fontes, notadamente os advindos da posse de ativos financeiros e não-financeiros).

${ }^{32}$ Nas seguintes passagens, Kuznets (1955), ao mesmo tempo em que apregoa a necessidade de dados mais abrangentes e completos (e reconhece a precariedade das informações disponíveis), ainda reforça seu
} 
dados de registros oficiais de Imposto de Renda para compreender de forma mais adequada a trajetória e a composição de rendimentos no topo da distribuição - onde, de fato, a concentração da renda e da riqueza se efetivou, a partir dos anos 2000.

A compreensão do fenômeno do rentismo e de seus desdobramentos sobre o padrão de acumulação exigem que a concentração econômica seja analisada em conjunto com a concentração de poder político, conforme ponderam estudos como os de Bonica et ali (2013), Dedecca (2012), Galbraith (2018; 2002), Reich (2017) e Wade (2005), entre outros. Nesse sentido, a definição do conceito de "income defense industry", por parte de Winters (2011), esclarece aspectos que elucidam a natureza das relações políticas moldadas dentro da atual ordem democrática com os negócios do setor privado. Os integrantes da "indústria de defesa da renda" incluem advogados tributaristas, escritórios de contabilidade ou de advocacia empresarial, "expoentes" da mídia e também diversos acadêmicos. No limite, a atuação destes profissionais é devotada, principalmente, a influenciar a legislação dos diferentes países, atuando também dentro dos parlamentos ${ }^{33}$.

Assim, fica claro como, sob a ordem capitalista atual, os conflitos de classes e os interesses específicos de grupos econômicos e financeiros vão se transladando do espaço físico das plantas produtivas das empresas e dos ambientes de trabalho nos bancos para disputas direcionadas à elaboração dos orçamentos públicos (incluindo, por exemplo, as questões relacionadas aos impostos, através da busca de justificativas para isenções tributárias) e também devotadas à regulação das atividades econômicas, notadamente as financeiras e as de grandes grupos empresariais. Como consequência, a maneira pela qual funciona a Democracia dos tempos atuais acentua a concentração de renda e de riqueza,

argumento segundo o qual o processo de desenvolvimento então vigente poderia estar sendo objeto de melhoria de perfil distributivo, caso estivessem disponíveis informações mais completas. Primeiro, o autor destaca estar trabalhando com dados de renda bruta ("first, the data are for income before direct taxes and exclude contributions by government (e.g., relief and free assistance). It is fair to argue that both the proportion and progressivity of direct taxes and the proportion of total income of individuals accounted for by government assistance to the less priviledged economic groups have grown during recente decades" (KUZNETS, 1955; $p$. 5). E, a seguir, ele pondera que, se dados mais abrangentes e completos estivessem disponíveis, ele poderia calçar de forma mais robusta seu argumento central, segundo o qual o processo de desenvolvimento daquele período havia gerado redução da desigualdade de renda entre os indivíduos (famílias): "It follows that the distribution of income after direct taxes and including free contributions by government would show an even greater narrowing of inequality in developed countries with size distributions of pretax, ex-government-benefits income similar to those for the United States and United Kingdom" (KUZNETS, 1955; p. 5).

${ }^{33}$ Para ilustrar as atividades da "income defense industry", vale citar as seguintes passagens de Winters (2011): "Since ancient times, taxation has always been a central and conflictual matter in political economy. Tax rates and burdens are a direct reflection of power. Although discussions can be mind-numbing, who pays taxes and how much they pay is linked to important notions of justice, fairness, morality, legitimacy, and citizenship" (pág. 212); e também: “(...) "Both as service providers and as political agents, the Income Defense Industry exists only because of the substantial material threats oligarchs face and the material power they exercise to counter them. This argument specifies the interests oligarchs have and traces the mechanisms through which power is used - and political outcomes are achieved - to address those interests" (pág. 214). 
através de novas formas de regulação pública ${ }^{34}$ e crescente mercantilização das campanhas políticas e da execução dos mandatos parlamentares.

Estudo de Bonica et ali (2013) trata dos EUA, mas suas principais conclusões podem ser generalizadas. Os autores mostram como, no funcionamento da democracia nos tempos atuais, as práticas parlamentares, tanto de Republicanos, como de Democratas, têm tomado decisões que promovem desregulamentação dos mercados de trabalho e financeiros, políticas tributárias regressivas e uma reversão do papel das políticas redistributivas que haviam caracterizado a sociedade americana desde o New Deal dos anos 1930.

O referido estudo (Bonica et ali, 2013) mostra também que o próprio processo de crescente desigualdade amplia a descrença na atividade política, notadamente entre as principais vítimas desse cenário. Dados reunidos pelos autores revelam que os pobres comparecem cada vez menos às urnas, ao mesmo tempo em que as campanhas eleitorais (e pré-eleitorais - as primárias dos partidos políticos) recebem cada vez mais verbas contributivas das pessoas, notadamente das mais ricas. Desta forma, a execução do mandato parlamentar fica crescentemente condicionada aos interesses dos financiadores das campanhas, o que aprofunda as desigualdades de renda e de riqueza e reforça a concentração de poder político e econômico.

\section{Conclusão}

A contribuição de Kuznets (1955) está entre os trabalhos fundadores da Teoria do Desenvolvimento que surge como uma temática ou disciplina específica dentro da Teoria Econômica a partir do pós-segunda guerra. Seu trabalho também se revelaria, nas décadas seguintes, uma referência para o debate sobre a questão distributiva que se instalaria a partir daquele contexto peculiar que marcou a Guerra Fria. Sua análise é mais conhecida pelo esforço de interpretar os efeitos das mudanças ocorridas na estrutura produtiva (e de emprego) sobre o perfil distributivo de países desenvolvidos selecionados, mas ele também destacou fatos que, nas décadas seguintes, acabariam presentes na evolução do debate sobre a desigualdade.

Um dos temas mais importantes que também foram inaugurados pelas pesquisas de Kuznets remete ao esforço que pesquisadores sobre a questão distributiva empreenderam, desde então, de tentar relacionar e, mais importante ainda, estabelecer ordem de precedência ou de causalidade entre desigualdade econômica e crescimento econômico (ou desenvolvimento). Este aspecto do debate não foi tratado neste artigo. Há uma enorme quantidade de estudos feitos por pesquisadores individuais ou elaborados por organismos

\footnotetext{
${ }^{34}$ Entre elas, se destacam várias, como a (des)regulação das relações de Trabalho, a atividade da Justiça trabalhista, ou da Justiça em geral, nos países onde não há uma forma específica de Justiça dedicada a questões do trabalho; a regulação e normas de acesso aos benefícios do seguro-desemprego; as regras da previdência Social, notadamente no que afeta ao funcionamento do mercado de trabalho e à geração de renda e seu impacto sobre o dinamismo da própria economia; a relação entre as políticas educacionais e o mercado de trabalho (notadamente no que se refere às políticas de formação profissional) etc. Para mais detalhes acerca destas formas de regulação, ver: Dedecca $(2009 ; 2010)$.
} 
multilaterais sobre essa questão complexa (e, muitas vezes, pouco conclusiva). A produção desses trabalhos também demonstra a atualidade de que ainda se reveste a contribuição teórica de Kuznets ${ }^{35}$.

A reversão da trajetória igualitária da distribuição de renda nos países desenvolvidos, bem como o fracasso, na maioria dos países subdesenvolvidos, em lograr melhorias consistentes (na melhor das hipóteses, em alguns casos as mesmas mostrar-se-iam efêmeras e pouco relevantes) dos perfis distributivos, mesmo em países que conseguiram obter exitosos processos tardios de industrialização, colocaram a leitura conservadora/conformista do modelo de Kuznets sob escrutínio. O presente artigo versa sobre os países desenvolvidos, mas não é demais destacar que também nos países periféricos/subdesenvolvidos o "modelo" de Kuznets, de alguma maneira, revelou-se presente no debate sobre distribuição de renda, direta ou indiretamente. No caso brasileiro, por exemplo, o debate sobre os resultados distributivos dos anos do chamado "Milagre Econômico" dos anos 60/70 estava permeado pela leitura conservadora (feita pelos defensores do Regime Militar) da curva de Kuznets. Esta leitura peculiar (não a única possível, conforme pretendemos ter deixado claro) foi amplamente criticada por autores de uma linhagem keynesiana ou estruturalista em artigos reunidos em também já clássica coletânea organizada por Tolipan e Tinelli $(1975)^{36}$. Estava claro, a partir dos anos 1970, que as "etapas" do desenvolvimento (ROSTOW, 2010[1956]), tanto nos países

\footnotetext{
${ }^{35}$ Para ficarmos em alguns exemplos, vale mencionar alguns trabalhos, todos dos anos 2000. Estudos como os de Banerjee e Duflo (2003), Berg e Ostry (2008), Boix (2009), Boushley e Price (2014) e Forbes (2000) expõem resenhas abrangentes sobre o debate acerca da ordem de determinação entre desigualdade e crescimento. Os trabalhos de Ostry e Berg (2014) e Ostry, Berg e Tsangarides (2014) tomam partido da ideia segundo a qual tentativas de promover equidade tendem a prejudicar o crescimento econômico. Compêndios da OECD (2008; 2011; 2015), bem como ILO (2017), por outro lado, pendem em favor do argumento segundo o qual menor desigualdade conduz a melhor desempenho econômico (sociedades mais igualitárias tenderiam a exibir economias mais dinâmicas). Por outro lado, estudos do FMI (IMF, 2014; 2016) apresentam abordagens mais contidas e limitam-se a resenhar resultados encontrados por seus técnicos, muitas vezes adotando interpretações sobre as caraterísticas da mão de obra no mercado de trabalho (abordagem principalmente microeconômica) e seus efeitos sobre a distribuição pessoal da renda. Em estudo mais recente, porém, o FMI (IMF, 2017) assume uma postura mais abertamente em favor da ideia de que a desigualdade social e econômica corrói a coesão social e atrapalha o crescimento do PIB. Milanovic (2016; especialmente no capítulo 2) faz uma crítica original e robusta aos esforços de Kuznets, incorporando fatores geopolíticos na interpretação da evolução dos perfis distributivos dos países, especialmente para apoiar seu argumento segundo o qual "a curva de Kuznets" (ou seja, a queda da desigualdade, enquanto existiu) não foi uma fatalidade, mas esteve inserida em um contexto internacional, em certo momento histórico de expansão do capitalismo (e cenário da Guerra Fria). Ou seja, incorpora fatores políticos e institucionais, de uma forma mais abrangente do que a de Kuznets, que era um conservador anticomunista, mas um observador arguto do tema e um formulador teórico rigoroso. Milanovic (2016) também exibe o mérito de reconhecer que Kuznets jamais afirmou que a melhoria do perfil distributivo seria uma fatalidade (postura de autores conservadores que usaram o referido estudo de Kuznets para legitimar processos de concentração de renda e de riqueza, nos mais diversos momentos históricos - começando na época da Guerra Fria - e diferentes países), pois dependente de diversos fatores políticos, sociais e institucionais, ademais dos fatores econômicos.

${ }^{36} \mathrm{O}$ caso brasileiro, ou demais casos da América Latina não são objeto deste artigo, mas podem ser avaliados em trabalhos anteriores do autor. Ver, por exemplo, Mattos (2005), Mattos (2017), Barone, Bastos e Mattos (2017) e Mattos, Bastos e Barone (2018).
} 
desenvolvidos, como nos subdesenvolvidos, não necessariamente trilhariam um caminho de redução das desigualdades pessoais de renda.

O alerta feito por Kuznets de que faltavam, em meados dos anos 1950, dados e informações estatísticas suficientes para interpretar a complexidade do fenômeno da desigualdade nos países desenvolvidos seria reconhecido nas décadas seguintes. Da mesma forma, a superação destas limitações se constituiria em um dos principais motivos para a posterior proficuidade de estudos sobre o tema. As mudanças no cenário econômico internacional (notadamente em dois momentos decisivos, a saber: a "reversão" da curva de Kuznets a partir de 1980 e o reconhecimento, a partir do final da primeira década do século $\mathrm{XXI}$, de que a desigualdade tomava novos impulsos e sob condições especialmente nocivas, do ponto de vista social e econômico ${ }^{37}$ ) exigiriam adicionais formas de medição do fenômeno, somente viabilizadas pelo surgimento de novas fontes de dados e de técnicas para a extração dos mesmos e subsequente análise.

Também deve-se sublinhar que, embora pouco mencionada nos estudos que buscam interpretar a obra de Kuznets, ele também havia chamado a atenção para as ações dos Estados Nacionais no sentido de mitigar as desigualdades de renda entre as pessoas notadamente no que se refere ao papel da política tributária (progressiva, no caso ${ }^{38}$ ) e à atuação de políticas de transferências de renda em favor dos mais pobres. Em estudos dos anos seguintes, notadamente a partir da contribuição de Atkinson, um dos principais articuladores e defensores do Welfare State, tanto em seu país (Reino Unido) como nas demais nações europeias, ficava claro que a ação do Estado, tanto na regulação da atividade econômica, quanto na forma de desenhar políticas de transferências de renda ${ }^{39}$, seria

\footnotetext{
${ }^{37}$ A questão do 1\% mais rico e a "superconcentração" de renda, em ambiente de recrudescimento do rentismo e dos "supersalários", segundo alerta Piketty (2014), pode colocar em jogo a continuidade do processo de acumulação capitalista, as regras de convivência civilizatória dentro dos países e entre eles, e até mesmo a sobrevivência do planeta. Na mesma linha, Wade (2005) já alertava, mesmo antes da deflagração da crise do subprime, para os efeitos disruptivos que a crescente concentração da renda e da riqueza poderia promover sobre as regras de sociabilidade entre os povos e sobre questões humanitárias envolvendo migrações nacionais e internacionais catastróficas, espalhamento de fome, miséria e diversas outras mazelas sociais em todos os cantos do mundo (inclusive em países ricos, como os EUA). Também Therborn (2011), embasando seus argumentos na trajetória das narrativas sobre desigualdade desde os tempos do Iluminismo até os tempos atuais, pontua que a questão da desigualdade volta, nos anos recentes, com muita presença no debate econômico e social, da mesma forma que havia ocorrido já desde os séculos XVII e XVIII. O autor alerta para a complexidade da questão (que envolve aspectos políticos de difícil encaminhamento) e para as tragédias sociais e civilizatórias que este processo de acelerada concentração da renda e da riqueza tem provocado, nos mais diversos países (também ele aponta que o problema não se restringe aos países pobres).

${ }^{38}$ No contexto histórico em que Kuznets escrevia seu trabalho clássico (em cenário oposto ao descrito para os anos recentes), o autor chamava a atenção para o papel que fatores políticos afetavam a determinação do perfil distributivo, tornando-o menos desigual: "One group of factors counteracting the cumulative effect of concentration of savings upon upper-income shares is legislative interference and "political" decisions. These may be aimed at limiting the cumulation of property directly through inheritance taxes and other capital levies" (Kuznets, 1955; p. 9).

39 Atkinson (2015) mostra a importância dessa discussão, como quando ele defende a ampliação da base tributária e a adoção de políticas tributárias progressivas. Da mesma forma, seus estudos pioneiros sobre Welfare State (reunidos e organizados em Atkinson, 1995) não só revelam a tradição europeia em avaliar a
} 
fundamental para enfrentar a desigualdade econômica, em suas diversas dimensões. E mais: que o desgaste destes mecanismos tornaria o problema da desigualdade ainda mais preocupante. O próprio estabelecimento das economias dos "supersalários" a que alude Piketty (2014) decorre do esvaziamento da ação estatal em seu empenho (típico de quando esteve em pleno vigor o que Streeck (2018; p. 153) chama de "mixed economy" keynesiana das décadas do pós-II Guerra) em favor do enfrentamento das desigualdades. Piketty (2014) atribui essa elevada dispersão salarial ao fato de que as alíquotas marginais de imposto de renda para os rendimentos mais elevados tenham sido drasticamente reduzidas ${ }^{40}$ a partir dos anos 1980, notadamente nos países anglo-saxões.

A mudança na trajetória da desigualdade, a partir dos anos 1980, ressaltou a necessidade de se estudar o aspecto pessoal da distribuição da renda (conforme Kuznets fizera nos anos 1950). Foi nesse contexto, em que o capitalismo foi se tornando cada vez mais complexo (em contraponto, por exemplo, com o cenário "ricardiano", no qual cada pessoa recebia um rendimento decorrente de sua condição de classe ${ }^{41}$ ), que o aspecto pessoal da distribuição de renda se instala com mais vigor. $\mathrm{O}$ amadurecimento das transformações promovidas no pós-1980, com a definitiva derrocada do sistema que havia sido erigido em Bretton Woods (Belluzzo, 1995), não só promoveria maior desigualdade, mas a tornava mais complexa e multidimensional (DEDECCA, 2009; 2010). É a partir daí que se tornam mais comuns as ocorrências de diversas fontes de renda na conformação do orçamento familiar, mesmo nos casos de pessoas próximas aos patamares de renda média nas pirâmides distributivas dos respectivos países, acumulando, além de renda (ou rendas, no caso de multiple jobs) do trabalho, também rendimentos provenientes de transferências sociais ou decorrentes da posse de ativos financeiros ou não-financeiros de diversas modalidades, tornando mais complexas as formas de medição da desigualdade.

Neste contexto cada vez mais intrincado e contraditório surge o reconhecimento da necessidade de se incorporar outros fatores, que não os "estritamente econômicos", para explicar a expansão da desigualdade, em cenário no qual se amplia a precariedade do

trajetória da desigualdade comparando sua evolução antes e depois dos impostos, como também destacam o papel que a própria constituição dos Estados de Bem Estar Social teve, em cada país, no sentido de promover um desenvolvimento econômico ao mesmo tempo mais robusto e mais igualitário nos cerca de 25/30 anos do pós-segunda guerra. Ver também, sobre isto, Mattos (2009).

${ }^{40}$ Atkinson (2015) e Galbraith (2016) também destacam esse detalhe importante para o surgimento dos altos e altíssimos salários nas sociedades capitalistas desenvolvidas.

${ }^{41}$ Vale citar referência que Atkinson (2009) faz a trabalho de autoria de Lydall (1968), no qual este alerta para o fato de os processos de geração de renda (e também a configuração dos mercados de trabalho), pelo menos a partir da segunda metade do século XX, serem mais multifacetados do que os que animaram os trabalhos dos autores clássicos acerca da distribuição de renda na economia capitalista: "Adam Smith, Ricardo and Malthus took it for granted that landlords were rich, labourers were poor, and capitalists were somewhere in the middle...Much of the discussion of the problem of distribution is still carried on in these terms, despite the fact that it is well known that many landowners are poor, many employees earn more than some capitalists, many property-owners work and many workers own property“. Estas palavras de Lydall (1968) justificam a necessidade de se interpretar a desigualdade econômica e a distribuição de renda segundo o ponto de vista da distribuição pessoal das rendas, inclusive levando-se em consideração o fato de que muitas pessoas possuem mais do que uma fonte de renda nas sociedades capitalistas contemporâneas. 
trabalho ao mesmo tempo em que aumenta expressivamente o número de milionários e trilionários nos principais países capitalistas. É por isso que, nos anos mais recentes, surgem estudos que se debruçam na necessidade de compreender como as instituições moldam e são moldadas pela Democracia contemporânea, com desdobramentos nas decisões tomadas no âmbito dos Estados Nacionais no sentido de (des)regular as relações de trabalho e de atuar nas políticas públicas, bem como na gestão das políticas monetárias e físcais - tão decisivas para alimentar o "rentismo" e tudo o que ele representa. Ademais, é forçoso compreender que o próprio cenário de recessão, de aumento do desemprego e de ampliação da exclusão social são usados politicamente pelos grupos econômicos e financeiros mais fortes para justificar a suposta "necessidade" de se desconstituírem as políticas públicas e demais fundamentos do Estado de Bem Estar Social que havia sido estabelecidos no pósguerra, conforme se depreende da leitura do recente trabalho de Streeck (2018). Nesse contexto, a deterioração da representação parlamentar e o desgaste da própria atividade política acabam tendo serventia para que estes grupos que se beneficiam do próprio processo de (re)concentração da renda e da riqueza possam pressionar os respectivos Estados Nacionais a tomar as medidas em seu favor, promovendo a adoção de ulteriores medidas concentradoras de renda e de riqueza. É por isso que James Galbraith, em vários estudos recentes, alerta que o problema da desigualdade é de caráter eminentemente político.

Nas próximas décadas, certamente o debate sobre a distribuição de renda deverá se concentrar na "questão do 1\%" mais rico (e suas subdivisões), não apenas por causa do perfil de acumulação que caracteriza o Capitalismo contemporâneo, mas também por causa do espaço que se abre, no referido debate, para questões metodológicas, institucionais e políticas relacionadas à concentração de renda e de riqueza, todas elas também importantes para a compreensão da trajetória do perfil distributivo e da organização das economias e das sociedades dos tempos atuais e do futuro próximo (pelo menos).

Esta discussão encerra uma complexidade que abarca os diversos aspectos que devem estar envolvidos no esforço da compreensão dos diversos mecanismos que reproduzem a desigualdade econômica e a exclusão social, bem como seus efeitos cumulativos ao longo do tempo, não apenas porque os juros reais vão seguidamente incidindo sobre estoques mais altos de riqueza financeira (cuja presença, na composição da riqueza no topo da distribuição, supera as outras formas de apropriação da riqueza), mas também porque a própria expansão das desigualdades amplia a capacidade de seus beneficiários acumularem poder político que, por sua vez, vai gerar novas ou antigas e repetidas formas de influenciar medidas de expansão das iniquidades. 


\section{Agradecimentos}

$\mathrm{O}$ autor registra um agradecimento a Carlos Pinkusfeld Bastos, professorpesquisador no Instituto de Economia da UFRJ, por valiosos comentários feitos a uma primeira versão deste artigo. Da mesma forma, registra agradecimentos a pareceristas anônimos da revista. E os isenta por eventuais imprecisões ainda remanescentes nesta versão final.

\section{Referências}

AARON, H. Politics and the Professors. Washington DC: Brookings Institute, 1978.

ATKINSON, A.B. Desigualdade: o que pode ser feito? São Paulo: Ed. LeYa; 2015.

ATKINSON, A.B. Factor Shares: the principal problem of political economy? Oxford Review of Economic Policy; V. 25; N. 1; p. 3-16; 2009.

DOI: https://doi.org/10.1093/oxrep/grp007

ATKINSON, A.B. Bringing Income distribution in from the cold. The Economic Journal, V. 107, N. 441 (Mar., 1997), p. 297-321.

DOI: https://doi.org/10.1111/j.0013-0133.1997.159.x

ATKINSON, A.B. Incomes and the Welfare State: essays on Britain and Europe. Cambridge University Press, 1995.

ATKINSON, A.; BOURGUIGNON, F. Introduction: Income distribution today. In: ATKINSON, A.; BOURGUIGNON, F. (org.). Handbook of Income Distribution volume A. Oxford (UK): Elsevier, 2015.

ATKINSON, A.; PIKETTY, T.; SAEZ, E. Top incomes in the Long Run of History. Journal of Economic Literature, v. 49:1, p. 3-71; March 2011.

DOI: https://doi.org/10.1257/jel.49.1.3

BANERJEE, A.V.; DUFLO, E. Inequality and Growth: What Can the Data Say? Journal of Economic Growth, V. 8, N. 3 (Sep., 2003), p. 267-299.

DOI: https://doi.org/10.1023/A:1026205114860

BARONE, R.S.; BASTOS, P.P.Z., MATTOS, F.A.M. Capital Humano ou Capitalismo Selvagem? Um Balanço da Controvérsia Sobre Distribuição de Renda durante o "Milagre" Brasileiro. Revista de Economia Contemporânea (2017) 21(3): p. 1-25. DOI: https://doi.org/10.1590/198055272132

BASTOS, C.P.; BRITTO, G. Introdução. In: AGARWALA, A.N. e SINGH, S.P. (orgs.). A Economia do Subdesenvolvimento. Rio de Janeiro: Ed. Contraponto/Centro Celso Furtado de Economia para o Desenvolvimento, 2010 (segunda edição; revista).

BELluZZO, L.G. O Tempo de Keynes nos Tempos do Capitalismo. São Paulo: Editora Contracorrente; 2016. 
BELluZZO, L. G. O despotismo dos estoques. Carta Capital, 26, jun; 1996.

BELLUZZO, L. G. O declínio de Bretton Woods e a emergência dos mercados globalizados. Economia e Sociedade, Campinas: UNICAMP/ lE, jun.; 1995.

BERG, A.; OSTRY, J. Inequality and Unsustainable Growth: two sides of the same coin? Imf Staff Discussion Note. April 8, 2008. IMF.

BOIX, C. The Conditional Relationship between Inequality and Development. Political Science and Politics, v. 42, n. 4 (October 2009), p. 645-649. American Political Science Association. DOI: https://doi.org/10.1017/S1049096509990072

BOLLEN, K.A. Issues in the Comparative Measurement of Political Democracy. American Sociological Review, Vol. 45, No. 3 (Jun., 1980), pp. 370-390. Published by: American Sociological Association. DOI: https://doi.org/10.1007/BF02716903

BONICA, A.; McCARTHY, N.; POOLE, K.T.; ROSENTHAL, H. Why hasn't Democracy slowed rising inequality? Journal of Economic Perspective; v 27; n 3; Summer 2013 (p. 103-124). DOI: https://doi.org/10.1257/jep.27.3.103

BOUSHEY, H.; PRICE, C.C. How Are Economic Inequality and Growth Connected? A Review of Recent Research. October 2014. Washington Center for Equitable Growth.

CHESNAIS, F. A Mundialização do Capital. São Paulo: Xamã, 1996.

DALTON, H. Some Aspects of the Inequality of Incomes in Modern Communities. London: Routledge; 1920.

DEDECCA, C.S. Desigualdade, mas de qual falamos? Texto para Discussão, IE/UNICAMP; N. 168; out./2009.

DEDECCA, C.S. Trabalho, financeirização e desigualdade. Texto para Discussão, IE/UNICAMP; N. 174; abr./2010.

DEDECCA, C.S. Os países desenvolvidos e a desigualdade econômica. Economia e Sociedade, Campinas, n. 21, n.3 (46), p. 449-484, dez.2012.

DOI: http://dx.doi.org/10.1590/S0104-06182012000300001

ESPING-ANDERSEN, G. The Three Worlds of Welfare Capitalism. Cambridge: Polity Press, 1990.

FORBES, K. J. A Reassessment of the Relationship between Inequality and Growth. American Economic Review, v. 90, n. 4, 2000, p. 869-87.

DOI: https://doi.org/10.1257/aer.90.4.869

GALBRAITH, James K. Extreme Inequality Creates Global Disorder: and it's a problem that can only have a political solution. The Nation. June 22, 2018. (issue from July 16-23). 
GALBRAITH, James K. Inequality: what everyone needs to know. New York (NY): Oxford University Press, 2016.

GALBRAITH, James K. Inequality and Instability: a study of the world economy just before the great crisis. Oxford University Press, 2012 (a).

GALBRAITH, James K. How Economists have Misunderstood Inequality: an interview with James Galbraith. The Washington Post; May 3, 2012 (b).

GALBRAITH, James K. Inequality, unemployment and growth: new measures for old controversies. Journal of Economic Inequality, n.7; 2009 (p. 189-206).

DOI: https://doi.org/10.1007/s10888-008-9083-2

GALBRAITH, James K. A perfect crime: inequality in the age of Globalization. Daedalus, v. 131; n. 1; Winter, 2002.

GALBRAITH, James K. Created Unequal: the crisis in American Pay. New York (NY): A Twentieth Century Fund Book, 1998.

GALBRAITH, John K. The Affluent Society $\left(40^{\text {th }}\right.$ anniversary edition, updated and with a new introduction by the author). Mariner Books; 1998 [1958].

GALBRAITH, J.; KUM, H. Inequality and Economic Growth: Data Comparisons and Econometric Tests. The University of Texas Inequality Project. LBJ School of Public Affairs. The University of Texas at Austin. UTIP Working Paper Number 21. (April, 5th; 2002).

HOBSBAWM, E. Era dos Extremos: o breve século XX (1914-1991). São Paulo: Companhia das Letras; 1995.

ILO. Equality at Work: tackling the challenges. Genebra, 2007.

IMF. Redistribution, Inequality and Growth. IMF Staff Discusison Note. 2014.

IMF. Causes and Consequences of income inequality: a global perspective. IMF Staff Discussion Note. 2016.

KEISTER, L.A. The One Percent. The Annual Review of Sociology, 40. PP. 347-367; 2014.

KERSTENETZKY, C.L. O Estado do Bem Estar Social na Idade da Razão: a reinvenção do Estado Social no mundo contemporâneo. Rio de Janeiro: Elsevier Editora, 2012. DOI: https://doi.org/10.1146/annurev-soc-070513-075314

KRISTAL, T. Good Times, Bad Times: Postwar Labor's Share of National Income in Capitalist Democracies. American Sociological Review; v. 75(5), p. 729-763; 2010. DOI: https://doi.org/10.1177/0003122410382640

KUZNETS, S. Shares of Upper Income Groups in Income and Savings. Cambridge, Mass.: National Bureau of Economic Research; 1953. 
KUZNETS, S. Economic Growth and Income Inequality. American Economic Review, v. 45(1): p. 1-28; 1955. DOI:

KUZNETS, S. Os países subdesenvolvidos e a fase pré-industrial nos países avançados: uma tentativa de comparação. In: In: AGARWALA, A.N. e SINGH, S.P. (orgs.). A Economia do Subdesenvolvimento. Rio de Janeiro: Ed. Contraponto/Centro Celso Furtado de Economia para o Desenvolvimento, 2010 (segunda edição; revista). (artigo originalmente publicado em 1954).

LYDALL, H.F. The Structure of Earnings. Oxford, Clarendron Press, 1968.

MATTOS, F.A.M. Aspectos históricos e metodológicos da evolução recente do perfil distributivo brasileiro. São Paulo em Perspectiva, v. 19, n. 2, p. 135-149, abr./jun. 2005. DOI: http://dx.doi.org/10.1590/S0102-88392005000200011

MATTOS, F.A.M. Flexibilização do Trabalho: sintomas da crise. São Paulo: Ed. Annablume, 2009.

MATTOS, F.A.M. O debate sobre distribuição de renda ao longo do processo de desenvolvimento econômico no Brasil. Revista da ABET; v. 16; n.1; jan/jul 2017. DOI: https://doi.org/10.22478/ufpb.1676-4439.2017v16n1.36040

MATTOS, F.A.M., BASTOS, P.P.Z.; BASTOS, R.S. O "debate pioneiro" sobre distribuição de renda no Brasil: como o padrão de acumulação gestado no governo militar de 1964 afetou o perfil distributivo da economia brasileira. In: MARTINS, M.S.N.; CAMPOS, P.H.P.; BRANDÃO, R.V.M. (org.). Política Econômica nos Anos de Chumbo. Rio de Janeiro: Ed. Consequência, 2018.

MILANOVIC, B. Global Inequality: a new approach for the age of globalization. Cambridge (MA); London (England): The Belknap Press of Harvad University Press, 2016.

OECD. In it Together: why less inequality benefits all. OECD. 2015.

OECD. Divided we stand: why inequality keeps rising? OECD, 2011.

OECD. Growing unequal? - Income distribution and poverty in OECD countries. Paris: OECD, 2008.

OSTRY, J.; BERG, A. Treating Inequality with Redistribution: is the cure worse than the disease? February 26, 2014. IMF Blog.

OSTRY, J.; BERG, A.; TSANGARIDES, C. Redistribution, Inequality and Growth. IMF Staff Discussion; SDN/14/02. April, 2014.

PIKETTY, T. Les hauts revenus en France au XXème siècle: Inegalités et redistributions 1901-1998. Paris: Grasset; 2001. 
PIKETTY, T. Income Inequality in France, 1901-1998. Journal of Political Economy, v. 111(5): p. 1004-42; 2003. DOI: https://doi.org/10.1086/376955

PIKETTY, T. O Capital no Século XXI. Rio de Janeiro: Ed. Intrínseca; 2014.

PIKETTY, T.; SAEZ, E. Top Incomes and the Great Recession: Recent Evolutions and Policy Implications. IMF Economic Review; v. 61, n. 3. 2013 International Monetary Fund. DOI: https://doi.org/10.1057/imfer.2013.14

PLIHON, D. Desequilíbrios mundiais e instabilidade financeira. (A responsabilidade das políticas liberais: um ponto de vista keynesiano). Economia e Sociedade. Campinas (SP), n.7, p. 85-127. 1996.

REICH, R. How inequality erodes the foundation of modern societies. New York Times (on line). Jul.20; 2017.

ROINE, J. E WALDENSTRÖM, D. Long-Run trends in the distribution of income and wealth, In: ATKINSON, A.; BOURGUIGNON, F. (org.). Handbook of Income

Distribution - volume A. Oxford (UK): Elsevier, 2015, p. 467-592.

ROSTOW, W.W. A decolagem para o crescimento auto-sustentado. In: Agarwala, A.N. e Singh, S.P. (orgs.). A Economia do Subdesenvolvimento. Rio de Janeiro: Ed.

Contraponto/Centro Celso Furtado de Economia para o Desenvolvimento, 2010 (segunda edição; revista). (publicado originalmente em The Economic Journal, em março de 1956 - vol. 66; issue 261-, sob o título "The Take-Off into Self-Sustained Growth").

STREECK, W. Tempo Comprado: a crise adiada do capitalismo democrático. São Paulo: Ed. Boitempo, 2018.

THERBORN, G. Inequalities and Latin America: from the Enlightenment to the $21^{\text {st }}$ Century. desiguALdades.net (Research Network on Interdependent Inequalities in Latin America). Working Paper n.1; 2011. DOI: https://doi.org/10.17169/REFUBIUM-23276

TINBERGEN, J. Income Distribution. Amsterdam: North-Holland; 1975.

TOLIPAN, R. e TINELLI, A. C. (org.). A Controvérsia Sobre Distribuição de Renda e Desenvolvimento.2. ed. Rio de Janeiro: Zahar Editores, 1975.

WINTERS, J.A. Oligarchy. Cambridge University Press, 2011.

WADE, R.H. Does Inequality Matter? Challenge, v. 48, n. 5 (September-October 2005), p. 12-38. DOI: https://doi.org/10.1080/05775132.2005.11034312 